\title{
Research on 3G Terminal-Based Agricultural Information Service
}

\author{
Neng-fu Xie and Xuefu Zhang \\ Agricultural Information Institute, The Chinese Academy of Agricultural Sciences Key \\ Laboratory of Digital Agricultural Early-warning Technology, Ministry of Agriculture, \\ Beijing 100081, P.R. China \\ \{xienengfu, zhangxuefu\}@caas.cn
}

\begin{abstract}
In order to solve the farmer's agricultural production information' acquisition problems with a 3G terminal, a 3G-terminial agricultural information service system method is proposed in the paper. With the advent of $3 \mathrm{G}$ and WLAN technologies, the rural and urban areas in which $3 \mathrm{G}$ coverage is complemented by WLAN deployments is becoming available. The agricultural information services limited by network bandwidth and geography will be changed completely. In the paper, we will propose an architecture of the $3 \mathrm{G}$ terminial agricultural information service. First, we present the design and implement of the GAIS architecture for mobile multimedia information service. Then the agricultural content-based information services are described in detail. Finally, we present a prototype agricultural information service to show our experiment for the agricultural information service in a mobile information context.
\end{abstract}

Keywords: 3G terminal, service design, agricultural information, push technology.

\section{Introduction}

With the urgent demand of agricultural information for farmers and quick development of telecommunication industry in china, the convenience, quickness and validity of agricultural information service are becoming more important [1]. The mobile phone has been described as the most likely modern digital device to support economic development in developing nations [5, 7]. Tapan presented CAM - a framework for developing and deploying mobile applications in the rural developing world. Supporting minimal, paper-based navigation, a simple scripted programming model and offline multimedia interaction, CAM is uniquely adapted to rural user, application and infrastructure constraints [3, 4]. The shortage of agri cultural information, poor telecommunication networks and uncoordinated information resources are crucial problems facing agricultural information sources in china. The 3G technology will enable a wide range of services and applications in rural areas with support of multimedia and positioning, which will bring novel applications with high impact for the farmers. Combined with modern web and data management 
technologies application in agricultural domain can bring new agricultural applications and services for agricultural production. The mobile phone is no longer just an audio communication tool but capable of providing additional integrated functions. The various features of mobile phone, which make it versatile, are SMS, MMS, GPRS [2].

The advent of $3 \mathrm{G}$ and WLAN technologies in the recent years open a way for sign language based services in mobile and wireless settings, which bring the applications and services come on stream. Third generation mobile network (3G) is the latest advancement in the field of mobile technology. Providing high bandwidth communication of $8 \mathrm{kbit} / \mathrm{s}-2 \mathrm{Mbit} / \mathrm{s}$ and a revolutionary introduction of multimedia services over mobile communication, it aims to make mobile devices into versatile mobile user terminals[8]. TD-CDMA (Time Division CDMA) wireless technology in china can meet the rapidly growing demand for mobile broadband services in agricultural information systems. The mobile information services will make it easier and quicker to provide agricultural information services in today's more complex web environment.

The agricultural information services limited by network bandwidth and geography will be changed completely with the $3 \mathrm{G}$ network coverage to rural area, which will help solve the problem of "last kilometer" in agricultural informationization. In the paper, we will develop an agricultural information system, which can gather, manage agricultural multimedia information resources, and push certain agricultural production technology information to the customized terminals.

The paper is structured into four main sections. Section 2 presents the terminal based agricultural information service architecture, which provides a software framework that aims to describe our need and the main components. In section 3 , the GAIS-based prototype system is presented and describes the agricultural contentbased information services in detail. Finally, Section 5 provides some conclusions and summary remarks.

\section{The GAIS Architecture Design}

The terminal -based agricultural information service (GAIS) architecture is the framework and soul of the agriculture information system deciding the system functions and information service. As showed in Fig. 1, the GAIS architecture is composed of our logic tires from the terminal client side to the server side: $3 \mathrm{G}$ terminal tier, portal service tier, $3 \mathrm{G}$ network tier and service center tier. At the fat server side, we provide an environment that integrates related different agricultural information sources into the agricultural information center. The source can be deleted, added and indexed diametrically. The center will also provide Update Tool guarantees that all data are always up to- date, manage the $3 \mathrm{G}$ terminal configure, and present enriched content on $3 \mathrm{G}$ terminals with limited user interface i.e. small screens and simple keyboards. 


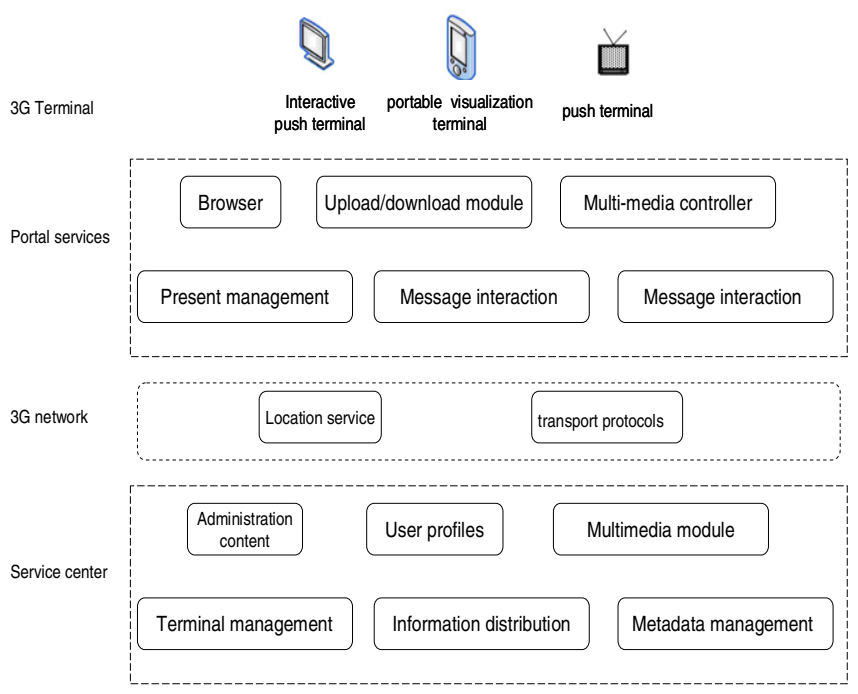

Fig. 1. The GAIS Architecture

\subsection{Agricultural Information Service Center Tier}

The service center tier manages and stores the agricultural information of the whole system, and decides the information exchange between the $3 \mathrm{G}$ terminal and service center according the setting of the terminal in the system.

The administration content module is designed for the data adding deleting and querying in agricultural information center. It will control the data quality of different databases, data service, and data clustering. The metadata management will help users find the information they required easily. The information meta-data is building an object-oriented repository technology that is integrated with agricultural meta data management that process metadata, which will provide a united category that organize the information in information center, and a standard of the information' store, and support exchange of model data. The metadata-based information service will provide a united interface for users to access the information by metadata-based information category. The information distribution is about assuring that the right agricultural information is available to the right agricultural users. In order to distribute the information to the users timely, we will build 3G-based information distribution service, by which the information will be accessed with the $3 \mathrm{G}$ terminals. In the means, the information distribution will help the communication between the users and the information center.

\subsection{G Network Tier}

In the near future, wireless networks will appear with greater ubiquity, from public access networks offering connectivity in agricultural information services, to telecoms 
operated 3G and 4G networks, especially TD-SCDMA network into rural areas in china, which allows 9 hundred million of farmers access to services as important and varied as information acquisition, health care, education, and financial and governmental services. The $3 \mathrm{G}$ network tier is mainly implementing the information exchange the $3 \mathrm{G}$ terminal and data server in TD-SCDMA network. Indeed our simulations are based on the following two assumptions: 1) full TD-SCDMA network coverage to rural area; 2) TD-SCDMA link always on, which we argue that are realistic assumptions in typical scenarios.

\subsection{Portal Service Tier}

The portal service tire contains a group service functions for the terminal, which can customized its necessary function, such as multimedia browsing, upload/download, multimedia controller, present management, message interaction and message interaction. The portal service tire can optimize the communication process and may offer mobile service enhancements, such as location, privacy, and presence based services. It communicates with the Web Server using the standard Internet protocols such as HTTP/HTTPS.

\subsection{3G Terminal Tier}

The mobile terminals must be seen as complex microelectronics assemblies that are attached to sophisticated network-based system. The $3 \mathrm{G}$ terminal tier is a carrier of the client of 3G-based Mobile agricultural information service. The client can store the information coming from the service center for offline browsing, and contain a microbrowser that the GUI and is analogous to a standard Web browser, which can accept the request agricultural information and send message to the service center that makes a plan, and pushes the information to the users' $3 \mathrm{G}$ mobile terminal by $3 \mathrm{G}$ network.

\section{GAIS-Based Prototype System}

Based on GAIS hierarchy and the actual needs of the project, the entire system is divided into two parts: service centers subsystem and mobile terminal subsystem, which constitute a service whole. The service center' functions contain: 1) It manages all the registered $3 \mathrm{G}$ terminals and gives orders for pushing information and emergence notification to the terminals; 2) It can put the $3 \mathrm{G}$ terminals into different groups according to the region to ensure that the pushed information and emergence notification is closely related with the farmers' requirements; 3) The service center manages the agricultural information and provides real-time dynamic information to the client-side. And it receives the request and processes it then return the result. The service center operation interface is showed in the Fig. 2. The mobile terminal subsystem is mainly used to store the information pushed by the service center, and browses video on demand. The mobile terminal subsystem can also send technology questions using text and picture to the server, and accept the result. The service center operation interface is showed in the Fig. 3. 


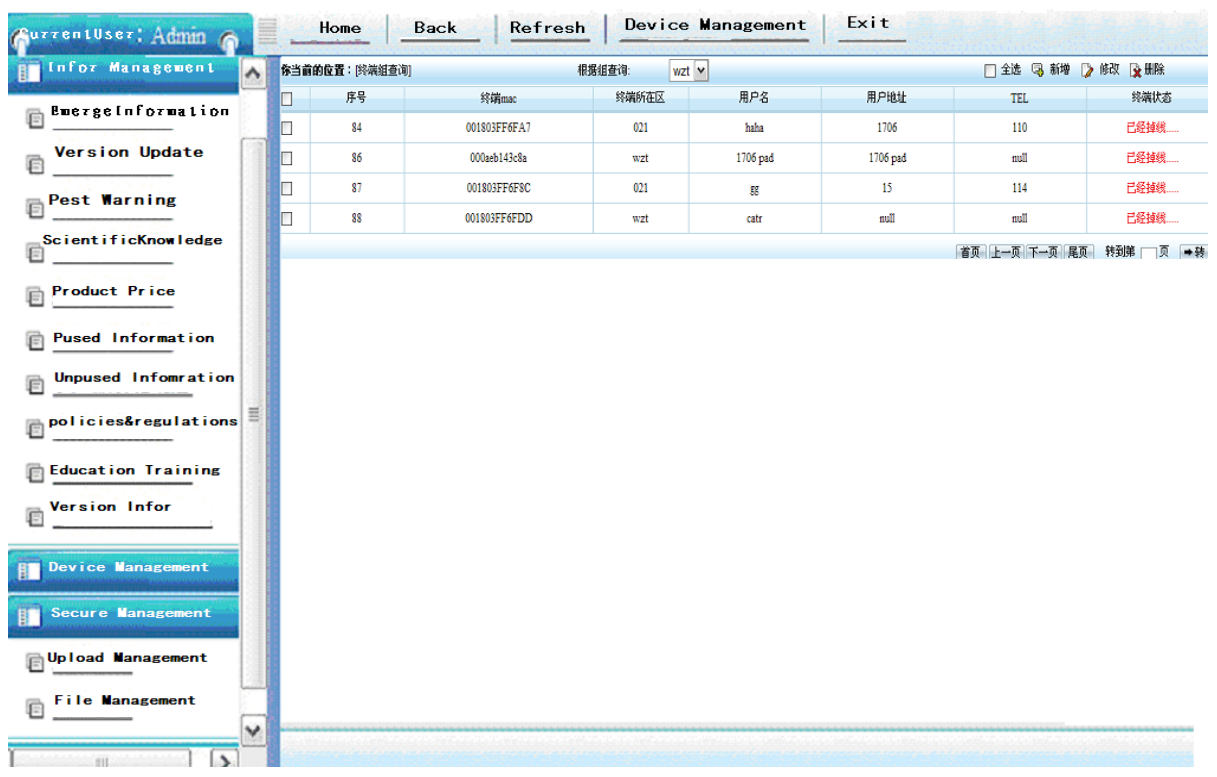

(a) The service center portal interface

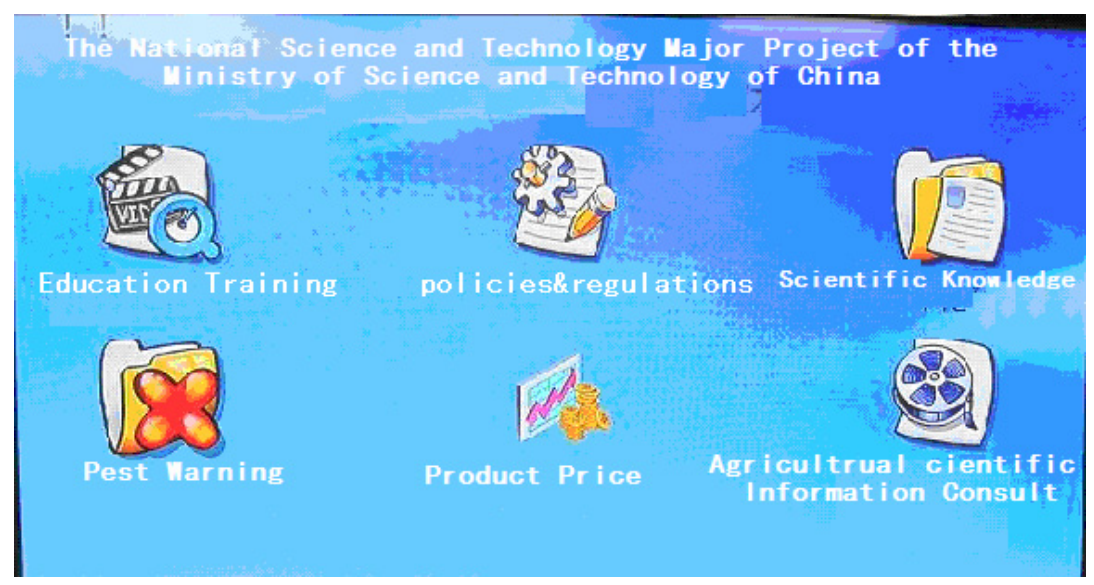

(b) The mobile terminal operation interface

Fig. 2. The system inferace based on GAIS hierarchy

The first applications testing wireless accesses was implemented for agricultural information provided by central information center, such as agricultural production technology, pest warning, Agricultural science and technology popularization, and farm product price, etc. The application have been supported by Special Project on of The National Department of Science and Technology "TD-SCDMA based application development and demonstration validation in agriculture informationization", which got very good effect to solve the problem of "last kilometer" in Chinese rural. 


\section{Conclusion}

In the paper, we have proposed an architecture of the 3G-terminial agricultural information service, which is the key and core of 3G-based information service system. In the paper, we also discussed how to push agricultural the information to the farmers and how the farmers get the agricultural production needs' technologies by communication with the system. And a prototype system is designed and developed based on the GAIS architecture which is composed of four logic tiers. The prototype system can push the information to the $3 \mathrm{G}$ terminal for the farmer' demands and the $3 \mathrm{G}$ terminal can also communicate with the system for getting the agricultural expert answer by asking questions, which proves that the architecture is feasible. In the future, we will make further study on the terminal information service development and the system demonstration.

Acknowledgments. The work is supported by the National Science and Technology Support Program (No.2011BAH10B01) and the special fund project for The CAAS scientific and technological fund project "Research on $3 \mathrm{G}$ information terminal-based rural multimedia information service" (No.201219).

\section{References}

1. Xie, N.F., Wang, W.S.H.: Research on 3G Technologies-Based Agricultural Information Resource Integration and Service. In: Li, D., Zhao, C. (eds.) CCTA 2009. IFIP AICT, vol. 317, pp. 114-120. Springer, Heidelberg (2010)

2. Dhaliwal, R.K., Joshi, V.: Mobile Phones - Boon to Rural Social System. Literacy Information and Computer Education Journal (LICEJ) 1(4), 261-265 (2010)

3. Parikh, T.S.: Using Mobile Phones for Secure, Distributed Document Processing in the Developing World. IEEE Pervasive Computing 4(2), 74-81 (2005)

4. Parikh, T.S., Lazowska, E.D.: Designing an architecture for delivering mobile information services to the rural developing world. In: Proc. WWW 2006, pp. 791-800 (2006)

5. The real digital divide. The Economist (March 2005)

6. Bi, J.F., Wang, L., Wang, Y., Liang, D.S.: Research of Mobile Spatial Information Service Based on Open Framework. In: GSEM 2009, pp. 106-108 (2009)

7. Guan, F.-Y., Long, S.-T., Huang, J.: Research on Rural Mobile Information Service in 3G Era. Sci-Tech Information Development \& Economy (2011)

8. Yilin, Z.: Standardization of mobile phone positioning for $3 \mathrm{G}$ systems. IEEE Communications Magazine 40(7), 108-116 (2012) 